\title{
Coastal acidification in summer bottom oxygen-depleted waters in northwestern-northern Bohai Sea from June to August in 2011
}

\author{
ZHAI WeiDong ${ }^{1,2^{*}}$, ZHAO HuaDe ${ }^{1,2}$, ZHENG Nan $^{1} \&$ XU Yi ${ }^{2}$ \\ ${ }^{1}$ Key Laboratory for Ecological Environment in Coastal Areas (State Oceanic Administration), National Marine Environmental Monitoring \\ Center, Dalian 116023, China; \\ ${ }^{2}$ State Key Laboratory of Marine Environmental Science, Xiamen University, Xiamen 361005, China
}

Received September 20, 2011; accepted November 30, 2011; published online January 31, 2012

\begin{abstract}
Dissolved oxygen (DO) and $\mathrm{pH}$ in the central part of the Bohai Sea were surveyed in late June and late August, 2011. During the June cruise, the bottom DO was in the range of 215-290 $\mu$ mol- $\mathrm{O}_{2} \mathrm{~kg}^{-1}$ (i.e. $85 \%-115 \%$ of the saturation level), and the bottom $\mathrm{pH}$ was in the range of 7.82-8.04 on the total-hydrogen-ion scale. In August, however, both the bottom DO and the pH had significantly declined in the northwestern-northern near-shore areas, where the water depth was no more than $35 \mathrm{~m}$. The lowest bottom DO was $100-110 \mu$ mol- $\mathrm{O}_{2} \mathrm{~kg}^{-1}$ (only $44 \%-47 \%$ of the June DO values) in the northern near-shore area, where the bottom $\mathrm{pH}$ was 7.64-7.68 on the total-hydrogen-ion scale (0.16-0.20 units lower than the June $\mathrm{pH}$ value). The largest decreases in DO and in $\mathrm{pH}$ were observed in the northwestern near-shore bottom waters, corresponding to declines of $170 \mu \mathrm{mol}-\mathrm{O}_{2} \mathrm{~kg}^{-1}$ (as high as $59 \%$ of the June DO value) and $0.29 \mathrm{pH}$ units, respectively. The greatest $\mathrm{pH}$ decline of $0.29 \mathrm{pH}$ units meant that the total-hydrogen-ion concentration doubled in the bottom waters from June to August. Based on field measurements of bottom DO/pH combined with a simplified model simulation, we suggest that respiration/remineralization-derived $\mathrm{CO}_{2}$ increased the acidity in the bottom oxygen-depleted waters of northwestern-northern near-shore areas in the Bohai Sea as a result of coastal red tides and/or marine aquaculture. This aquatic chemistry is suggested to be partially responsible for scallop-breeding failures in the northwestern Bohai Sea in summer 2011.
\end{abstract}

dissolved oxygen, pH, coastal hypoxia, coastal acidification, Bohai Sea

Citation: Zhai W D, Zhao H D, Zheng N, et al. Coastal acidification in summer bottom oxygen-depleted waters in northwestern-northern Bohai Sea from June to August in 2011. Chin Sci Bull, 2012, 57: 1062-1068, doi: 10.1007/s11434-011-4949-2

Dissolved oxygen (DO) and $\mathrm{pH}$ are essential parameters for the health of aquatic environments. Recently, seasonal bottom hypoxia (DO less than $90 \mu \mathrm{mol}-\mathrm{O}_{2} \mathrm{~kg}^{-1}$ or $2.8 \mathrm{mg} \mathrm{L}^{-1}$ ) in coastal ocean areas has tremendously increased in terms of frequency, severity, and areas affected, and this is considered to be one of the most pressing water-degradation problems in the world [1]. For example, seasonal hypoxic areas of $>10^{4} \mathrm{~km}^{2}$ have been well documented in the northern Gulf of Mexico and in the northwestern East China Sea off the Changjiang Estuary, with typical bottom DO values of $<60 \mu$ mol- $\mathrm{O}_{2} \mathrm{~kg}^{-1}$ in the summer [2,3]. The critical DO for a functional aquatic ecosystem has traditionally been

\footnotetext{
*Corresponding author (email: wdzhai@126.com)
}

considered to be $65 \mu$ mol- $\mathrm{O}_{2} \mathrm{~kg}^{-1}$ (i.e. $2 \mathrm{mg} \mathrm{L}^{-1}$ ) [2-4]. However, recent work shows that many aquatic organisms are affected at DO concentrations higher than $90 \mu$ mol- $\mathrm{O}_{2}$ $\mathrm{kg}^{-1}$ [5-7], although certain benthic species can tolerate DO values lower than this for several days to weeks [5]. Furthermore, critical DO values also depend on the temperature and the consequent metabolic rates of organisms, and therefore global warming is likely to exacerbate the effects of hypoxia [8]. A laboratory study has shown that the stress induced by hypoxia can make corals more vulnerable to invasive organisms, causing the corals to release symbiotic algae to reduce the danger, resulting in coral bleaching [9].

Usually, $\mathrm{pH}$ values are expressed on a logarithmic scale as $\mathrm{pH}=-\log _{10}\left[\mathrm{H}^{+}\right]$, where $\left[\mathrm{H}^{+}\right]$refers to the concentration of 
hydrogen ions. These are referred to the $\mathrm{pH}$ on the NBS or NIST scale. NBS refers to the National Bureau of Standards, which is now called NIST (National Institute of Standards and Technology, the US Department of Commerce). However, chemical oceanographers prefer using the $\mathrm{pH}$ on the total-hydrogen-ion scale $\left(\mathrm{pH}_{\mathrm{T}}=-\log _{10}\left[\mathrm{H}^{+}\right]_{\mathrm{T}}\right.$, where $\left[\mathrm{H}^{+}\right]_{\mathrm{T}}=$ $\left.\left[\mathrm{H}^{+}\right]+\left[\mathrm{HSO}_{4}^{-}\right]\right)[10,11]$. A CO2SYS software [12] shows that normal surface seawater (with a salinity range of 30-35 and a salinity-normalized total alkalinity of $2300 \mu \mathrm{mol} \mathrm{kg}{ }^{-1}$ ) in equilibrium with a clean atmosphere (with a $\mathrm{CO}_{2}$ partial pressure of $38.5 \mathrm{~Pa}$ ) at $25^{\circ} \mathrm{C}$ has a $\mathrm{pH}$ of $8.02-8.06$ on the total-hydrogen-ion scale or $8.16-8.20$ on the NIST scale.

A drop of $0.3 \mathrm{pH}$ units corresponds to a doubling of the $\mathrm{H}^{+}$concentration. In laboratory and mesocosm studies, a decrease of 0.2 to 0.3 units in seawater $\mathrm{pH}$ inhibits or slows calcification in many marine organisms, including corals, foraminifera, and some calcareous plankton [13,14]. Another laboratory study has shown that a $\mathrm{pH}$ level of $<7.8$ (on the NIST scale) will influence survival of a species of scallop (Chlamys farrei), which is extensively cultured around the Bohai Sea [15]. In a marine ecosystem affected by volcanic $\mathrm{CO}_{2}$ vents, $\mathrm{pH}$ values are $<7.6$ (on the NIST scale), and gastropod shells can dissolve at this $\mathrm{pH}$ [16]. Furthermore, recent studies have shown that increases in acidification and $\mathrm{CO}_{2}$ levels have negative effects on many aquatic organisms, including non-calcifying ones $[17,18]$.

The seasonal bottom hypoxic phenomenon has been proposed to be the result of coastal eutrophication and the subsequent algal blooms and/or red tides. Algae and other biogenetic particles sink to the bottom waters, where they are remineralized through oxygen-consuming processes. If local hydrological dynamics cannot enable recovery of the bottom DO, hypoxia may be caused by the oxygen consumption of bottom organisms. The integrated stoichiometry associated with these remineralization processes can be roughly characterized by the traditional Redfield equation:

$$
\begin{gathered}
\left(\mathrm{CH}_{2} \mathrm{O}\right)_{106}\left(\mathrm{NH}_{3}\right)_{16} \mathrm{H}_{3} \mathrm{PO}_{4}+138 \mathrm{O}_{2} \rightarrow 106 \mathrm{CO}_{2} \\
+16 \mathrm{HNO}_{3}+\mathrm{H}_{3} \mathrm{PO}_{4}+122 \mathrm{H}_{2} \mathrm{O}
\end{gathered}
$$

Equation (1) clearly shows that oxygen-consuming remineralization is associated with a significant release of $\mathrm{CO}_{2}$, which is a typical acidic gas. Coastal hypoxic waters therefore often have quite low $\mathrm{pH}$ values, i.e. coastal acidification. This coastal acidification is in general a regional and seasonal phenomenon. It is very different from ocean acidification induced by increases in atmospheric $\mathrm{CO}_{2}$ [19]. The latter effect occurs on a global scale and shows a clear tendency. Compared with the typical decline of $0.06 \mathrm{pH}$ units in the upper open ocean in the past 15 years [20], however, coastal acidification is characterized by a shortterm but very sharp $\mathrm{pH}$ drop of approximately $0.3 \mathrm{pH}$ units on a seasonal timescale [21], and is usually accompanied by a short supply of DO. Eutrophication-induced coastal acidification may therefore cause more stress to marine organ- isms. However, so far, only a few studies have been designed to understand the integrated effects of coastal hypoxia and acidification on marine organisms and ecosystems $[19,21]$.

The Bohai Sea, which has an area of $77000 \mathrm{~km}^{2}$ and a mean depth of $18 \mathrm{~m}$, is a shallow semi-enclosed marginal sea of the northwest Pacific. It is connected to the Yellow Sea through a narrow channel (Figure 1). The water exchange rate between the Bohai Sea and the Yellow Sea is quite limited. The Bohai Sea is surrounded by Hebei, Liaoning, and Shandong provinces, and Tianjin. All of these are fast-developing economic zones, and highly populated regions of China. During the past 20 years, increasing eutrophication has led to a high frequency of red tides in the Bohai Sea [22], especially in its three primary bays (i.e. Liaodong Bay in the northeast, Bohai Bay in the west, and Laizhou Bay in the south). Scallop-breeding failures have occasionally been reported. For example, during the years 1997 and 1998, several major scallop-breeding failures occurred in the summer around the Bohai Sea [15]. To uncover the possible causes of these failures, a series of laboratory studies were conducted. The results show that the tolerance of cultured scallop species to low pH values is very limited [15]. Surprisingly, so far, neither bottom hypoxia nor acidification in the Bohai Sea has been reported, although a slightly decreasing DO trend from 1979 through to 1999 has been documented in the central part of the Bohai Sea $[23,24]$.

\section{Materials and metheds}

During June 24-28, 2011 and August 23-25, 2011, we conducted two field surveys in the central part of the Bohai Sea, also touching the three primary bays of the Bohai Sea (Figure 1). Water samples for DO and $\mathrm{pH}$ determination were collected at 20-23 grid stations, including 19 repeat stations. Most of these sampling stations were quite shallow, with a water depth of 15-35 m (Figure 1). The northwestern sampling stations were near the two well-known scallopbreeding counties of Laoting and Changli (Figure 1), where scallop-breeding failures were reported in the summer of 2011 (http://news.xinhuanet.com/2011-08/25/c_121910529. $\mathrm{htm}$ ), with a preliminary loss estimated at more than ten million US dollars. The northwestern stations were also adjacent to one of the major industrial parks in China, i.e. the Caofeidian industrial park (Figure 1). Several of the northern sampling stations were located in the southern part of the highly eutrophicated Liaodong Bay (Figure 1).

During the two surveys, water samples were obtained at three to four depths using rosette samplers fitted with $8 \mathrm{~L}$ or 2.5 L Niskin bottles, which were mounted with ConductivityTemperature-Depth/Pressure (CTD) units (SBE911+ in June and SBE19+ in August, Sea-Bird Co., USA), onboard the $\mathrm{R} / \mathrm{V}$ Dongfanghong II (June) and R/V Yixing (August). The 


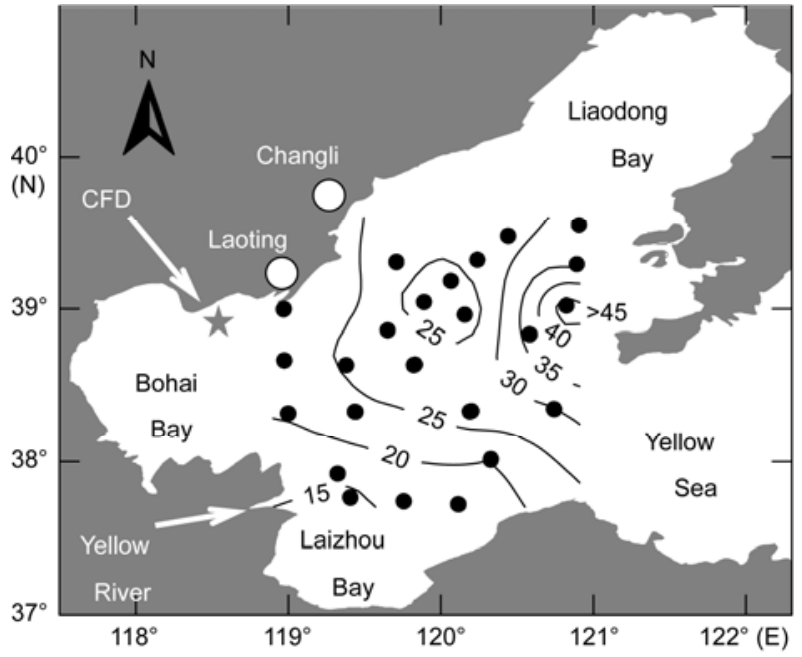

Figure 1 Area map and sampling sites. Isobaths of 15, 20, 25, 30, 35 and $40 \mathrm{~m}$ in the region under study are shown using thin lines. The three primary bays, the Caofeidian (CFD) industrial park, and the locations of the two scallop-breeding counties of Laoting and Changli are also marked.

bottom water samples were collected from a depth of 2-3 m above the sea bed.

Subsamples for DO analyses were collected, fixed, and titrated onboard, following the classic Winkler procedure. A small quantity of $\mathrm{NaN}_{3}$ was added during subsample fixation in order to remove possible interference from nitrites. Based on repeat determinations of the concentration of the $\mathrm{Na}_{2} \mathrm{~S}_{2} \mathrm{O}_{3}$ titration reagent used, the uncertainty of our DO data was estimated to be at a satisfactory level of $<0.5 \%$.

Subsamples for $\mathrm{pH}$ analyses were collected onboard using a procedure similar to that used for DO. They were preserved with $\mathrm{HgCl}_{2}$ and determined at $25.0^{\circ} \mathrm{C}$ within $6 \mathrm{~h}$ upon sampling. The precision $\mathrm{pH}$ analyzer (Orion $\mathrm{Star}^{\mathrm{TM}}$, Thermo Electron Co., USA) used was equipped with an
Orion ${ }^{\circledR}$ 8102BN Ross combination electrode (Thermo Electron Co., USA) against 2 or 3 standard buffers. During our field surveys, we used two sets of $\mathrm{pH}$ buffers. The first set included three NIST-traceable buffers, which were used during both cruises. Another set of $\mathrm{pH}$ buffers was used during the June survey only, and included two carefully prepared solutions of 2-amino-2-hydroxy-1,3-propanediol (tris) and 2-aminopyridine. These are traditionally used by chemical oceanographers as total-hydrogen-ion-scale $\mathrm{pH}$ buffers [10]. Based on parallel measurements in June using the two sets of $\mathrm{pH}$ buffers, we concluded that the $\mathrm{pH}$ data on the total-hydrogen-ion scale were lower than the NIST-traceable $\mathrm{pH}$ data by $0.143 \pm 0.006 \mathrm{pH}$ units (mean \pm standard deviation, $n=73$ ) in the Bohai Sea, which was comparable with the commonly accepted value for this difference [12]. Based on this result, we transferred the August NIST-traceable $\mathrm{pH}$ data to the total-hydrogen-ion scale, although we did not use total-hydrogen-ion-scale $\mathrm{pH}$ buffers during that cruise. The overall uncertainty of our $\mathrm{pH}$ dataset was estimated to be $0.01 \mathrm{pH}$ units.

\section{Results}

During the two surveys, the salinity distributions were in general homogeneous. Other than at a special station adjacent to the Yellow River Estuary, most salinity values at all depths ranged between 30.2 and 31.5. However, vertical temperature profiles showed a clear stratification in the summer in the northwestern-northern Bohai Sea (Figure 2). The warm surface waters (i.e. with relatively low density) mantled the relatively low-temperature bottom waters (i.e. with relatively high density). The seasonal stratification blocked interactions between the sea surface and bottom waters in the summer. As a comparison, in the southern part

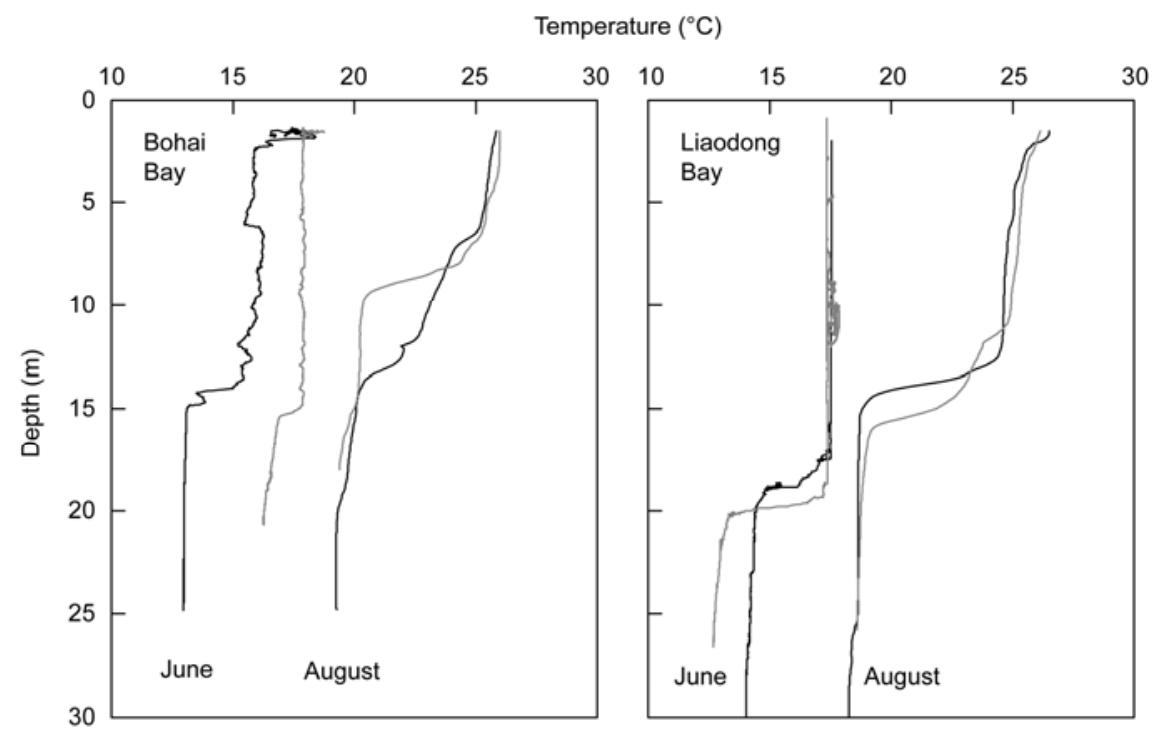

Figure 2 Typical vertical profiles of water temperature in the northwest (Bohai Bay) and the north (Liaodong Bay) during the two surveys. 
of the Bohai Sea, the generally homogeneous vertical temperature profiles (data not reported) showed that turbulent mixing dominated the water columns there during both surveys. This horizontal distribution of the thermocline is a typical summer pattern in the Bohai Sea [25].

During our June survey, the water column DO concentrations were in the range of $215-310 \mu \mathrm{mol}-\mathrm{O}_{2} \mathrm{~kg}^{-1}$ (Figure 3(a)), and the $\mathrm{pH}$ ranged between 7.82 and 8.12 (Figure 3(b)). Both parameters showed minor horizontal and vertical variations in June. From June to August, however, the hydrochemical status of the Bohai Sea changed greatly. In August, a much wider DO range of $100-280 \mu$ mol- $\mathrm{O}_{2} \mathrm{~kg}^{-1}$ (Figure 3(a)) and a wide $\mathrm{pH}$ range of 7.64-8.17 (Figure 3(b)) were obtained. The surface DO concentrations were in the range of $220-280 \mu \mathrm{mol}-\mathrm{O}_{2} \mathrm{~kg}^{-1}$ in August; these were only slightly lower than the surface DO values in June (Figure 3(a)). This minor difference was probably caused by the warming-induced decline in saturated DO concentration from June through to August. In fact, saturation data for surface DO (98\%-129\% in June versus 100\%-124\% in August) showed little differences between the two surveys. Similarly, the range of surface $\mathrm{pH}$ values in August (7.86-8.17) was very close to that in June (7.90-8.12) (Figure 3(b)).

In contrast, significant hydrochemical differences between the two surveys were observed in the bottom waters. In August, several quite low $\mathrm{DO}$ and $\mathrm{pH}$ values were found in bottom waters (Figure 3). In a zonal near-shore area located in the northwestern-northern Bohai Sea, where 20\% of the sampling sites were located, the bottom DO declined to $<135 \mu \mathrm{mol}-\mathrm{O}_{2} \mathrm{~kg}^{-1}$ (i.e. $<4 \mathrm{mg} \mathrm{L}{ }^{-1}$ ), although it had been $>215 \mu$ mol- $\mathrm{O}_{2} \mathrm{~kg}^{-1}$ in June. In the northern part of the Bohai Sea under investigation (i.e. southern Liaodong Bay), the lowest bottom DO was determined to be 100-110 $\mu$ mol- $\mathrm{O}_{2} \mathrm{~kg}^{-1}$ (Figure 4(a)). The bottom $\mathrm{pH}$ ranged between 7.64 and 7.75 in this zonal near-shore area. The lowest $\mathrm{pH}$
(7.64) was located in the bottom waters near Changli (Figure 4(b)). These characteristics of low DO and low $\mathrm{pH}$ in August were still detectable at a depth of $10 \mathrm{~m}$ above the sea bed at several stations (Figure 3).

\section{Discussion}

We calculated the declines in bottom DO at the repeat stations. In the northwestern-northern near-shore areas, bottom DO declines were revealed to be 123-171 $\mu$ mol- $\mathrm{O}_{2} \mathrm{~kg}^{-1}$ (Figure 4(c)), as high as 53\%-59\% of the June DO value. The greatest DO decline $\left(171 \mu\right.$ mol- $\left.\mathrm{O}_{2} \mathrm{~kg}^{-1}\right)$ was determined at the repeat station near Laoting (Figure 4(c)); this is similar to the typical bottom apparent oxygen utilization level observed in the hypoxic area in the northwestern East China Sea off the Changjiang Estuary [3]. Since water stratification occurred in the summer months in this region (Figure 2), we assumed that possible DO recovery (either via vertical mixing plus air-sea exchange or via horizontal transport) was negligible. We therefore suggest that these declines in bottom DO in the two months can be regarded as a rough estimate of the apparent DO depletion rates, i.e. approximately $2.0-2.8 \mu \mathrm{mol}-\mathrm{O}_{2} \mathrm{~kg}^{-1}$ were consumed per day in the northwestern-northern near-shore bottom waters; these are similar to the typical values for field-measured summer respiration rates in the East China Sea shelf-waters [26].

Similar to the bottom DO decreases, the bottom $\mathrm{pH}$ values declined by more than $0.20 \mathrm{pH}$ units in the northwestern-northern near-shore areas (Figure 4(d)). The largest $\mathrm{pH}$ drop of $0.29 \mathrm{pH}$ units was observed at the repeat station near Laoting (Figure 4(d)). These $\mathrm{pH}$ declines mean that the total-hydrogen-ion concentrations increased by $60 \%-100 \%$ from June to August in the northwestern-northern near-shore

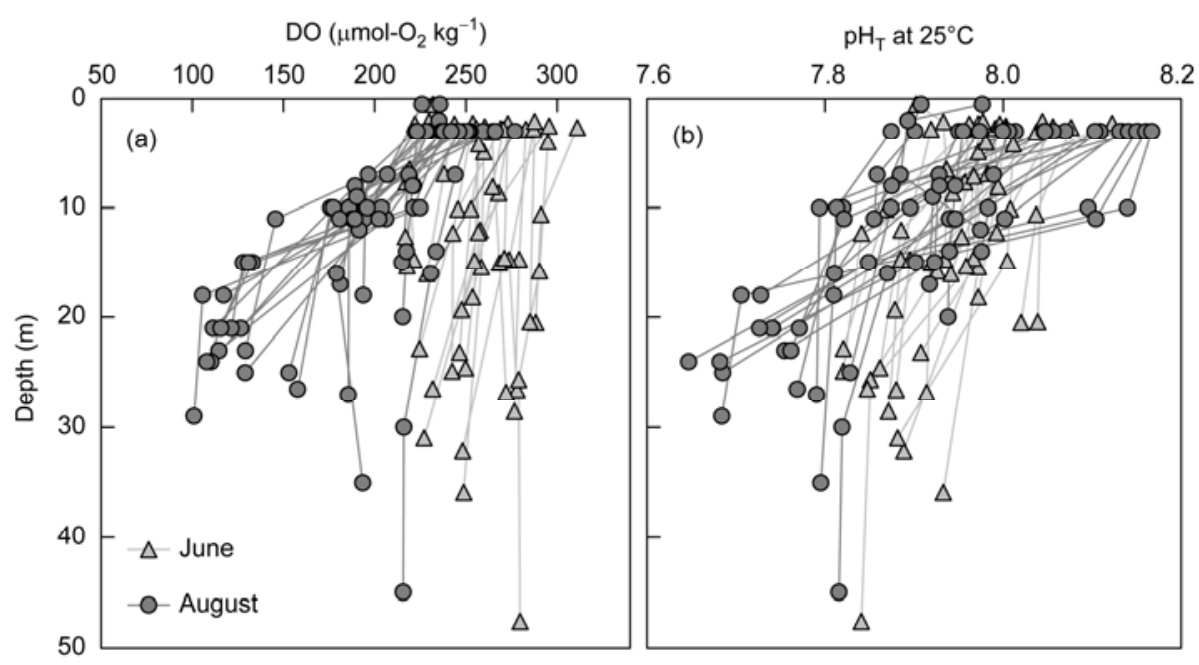

Figure 3 Vertical profiles of DO (a) and pH (b) at all sampling sites during the June survey (triangles) and the August survey (gray circles). Most of these sites were repeatedly sampled during the two cruises. The deepest water sample at every site was from the bottom water at a depth of $2-3 \mathrm{~m}$ above the sea bed. 

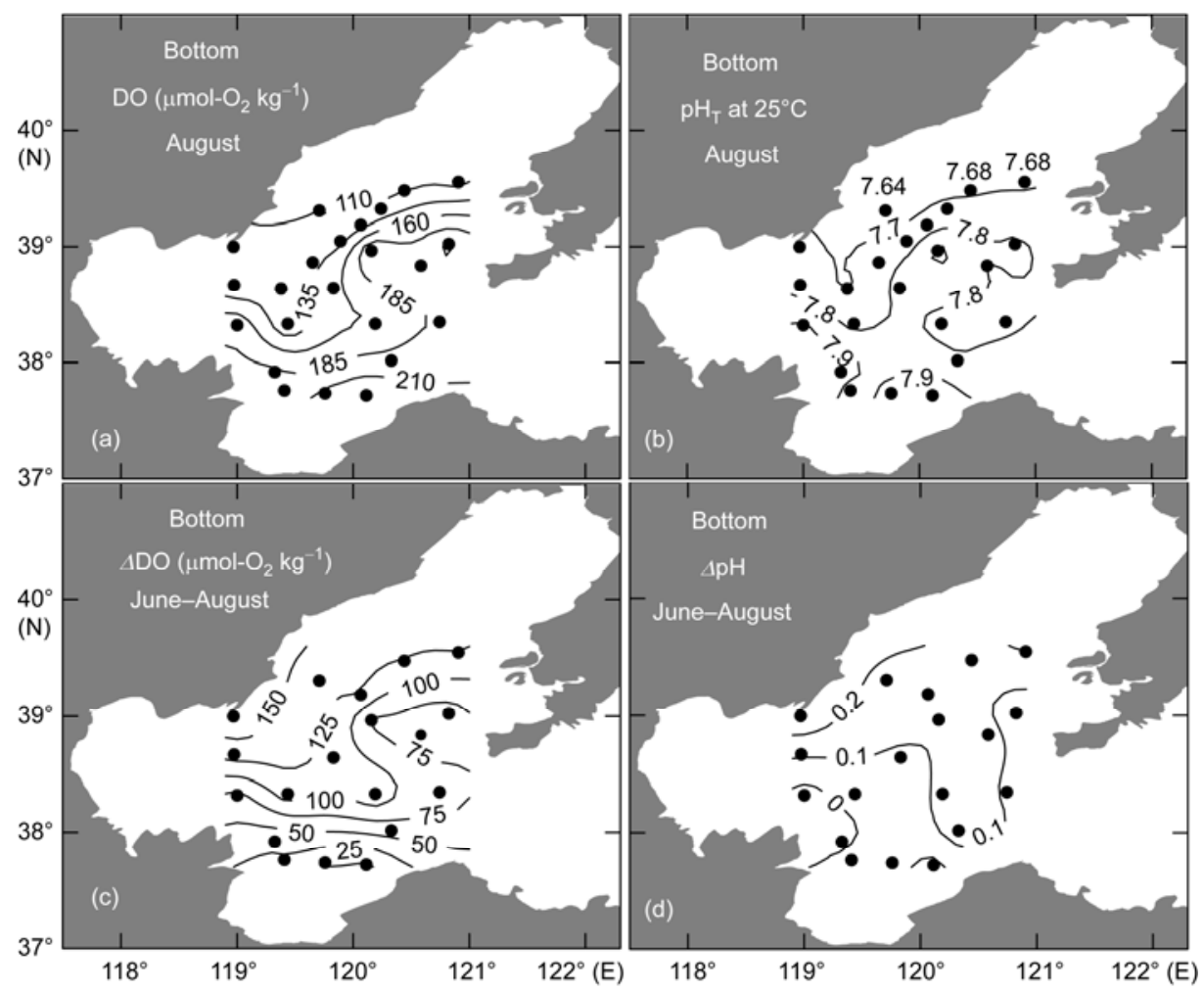

Figure 4 Distributions of August bottom DO (a) and August bottom pH (measured at $25^{\circ} \mathrm{C}$ ) (b), and differences in bottom DO (c) and bottom $\mathrm{pH}(\mathrm{d})$ between June and August.

bottom waters. This coastal acidification in two months is equal to the surface acidification predicted to be induced by increasing atmospheric $\mathrm{CO}_{2}$ in the next 50-100 years. Such a sudden acidification would undoubtedly do great harm to the local marine aquaculture [15]. In the southern and southeastern areas, however, there was no difference between the bottom $\mathrm{pH}$ in the two surveys.

Based on the significant positive correlation between the bottom $\mathrm{DO}$ and $\mathrm{pH}$ in the Bohai Sea during the two summer surveys (Figure 5), we suggest that both the bottom DO depletion and the coastal acidification were induced by remineralization of biogenic particles (eq. (1)). These biogenic particles were supplied either by coastal red tides or by near-shore marine aquaculture. We observed a significant red tide during the June survey at the near-shore sampling site near Laoting. At that site, chlorophyll a concentrations (26-33 $\mathrm{mg} \mathrm{m}^{-3}$, Shang et al., unpublished data) were very high at all depths in the water column, and the water column DO concentrations (288-311 $\mu$ mol- $\mathrm{O}_{2} \mathrm{~kg}^{-1}$ ) were $16 \%-29 \%$ above the air-saturated level. Both indicated that a red tide occurred at that site. This red tide may also affect nearshore waters near Changli, and may disappear in early July (http://news.xinhuanet.com/2011-08/25/c_121910529.htm). As a result of this red tide, both the largest apparent oxygen depletion and the greatest $\mathrm{pH}$ decline were observed in $\mathrm{Au}$ gust in the near-shore repeat station near Laoting (Figure 4), where we observed the above-mentioned red tide in June. If

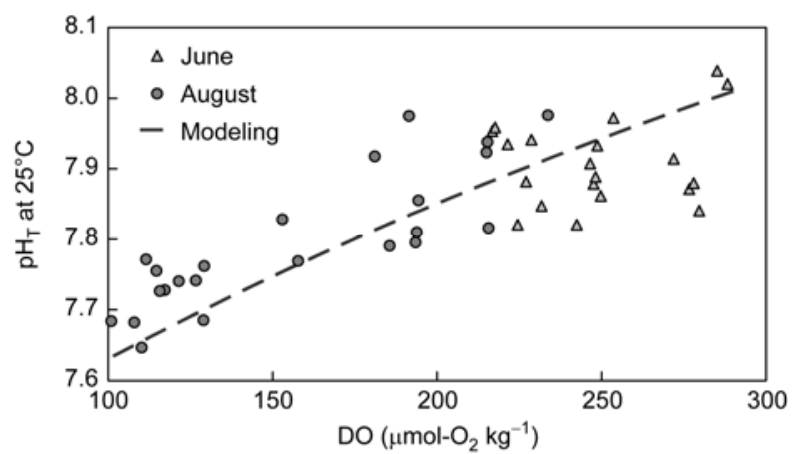

Figure 5 Relationship between bottom $\mathrm{pH}$ and DO in the Bohai Sea in the summer of 2011. The dashed line shows the simulated time-series relationship between bottom $\mathrm{pH}$ and $\mathrm{DO}$ variations at the near-shore repeat station in the northwestern Bohai Sea near Laoting. See the text for details. In this simplified model, we ignored the possible effects of air-sea exchanges and water-sediment exchanges. We also assumed that the timeseries variations at a specific site were comparable to the spatial variations in the whole sea-area.

we compare the largest bottom $\mathrm{pH}$ decline $(\Delta \mathrm{pH}=-0.29)$ with the greatest bottom apparent $\mathrm{DO}$ depletion $(\triangle \mathrm{DO}=$ $\left.-171 \mu \mathrm{mol}-\mathrm{O}_{2} \mathrm{~kg}^{-1}\right)$ at the near-shore repeat station near Lao-ting, a ratio of $\mathrm{pH}$ decline of $0.052 \mathrm{pH}$ units per DO depletion of $31 \mu \mathrm{mol}-\mathrm{O}_{2} \mathrm{~kg}^{-1}$ (i.e. $1 \mathrm{mg} \mathrm{L}{ }^{-1}$ ) is obtained. A similar ratio was also found in bottom hypoxic waters in the northern Gulf of Mexico [21].

To quantify this respiration-derived acidification, we 
calculated the relationship between the carbonate system and DO variations in the oxygen-depleted bottom waters, based on eq. (1) and the field-measured datasets of bottom DO, dissolved inorganic carbon, and total alkalinity in June. Then we used the CO2SYS software [12] to calculate the time-series relationship between $\mathrm{pH}$ and $\mathrm{DO}$ variations (the dashed line in Figure 5). The simplified simulation was modeled using a constant warming rate of $0.1^{\circ} \mathrm{C}$ per day and a constant DO depletion rate of $3.1 \mu \mathrm{mol}-\mathrm{O}_{2} \mathrm{~kg}^{-1}$ (i.e. $0.1 \mathrm{mg} \mathrm{L}^{-1}$ ) per day, from June 25 to August 30 . Figure 5 shows that the calculated $\mathrm{pH}-\mathrm{DO}$ relationship basically fitted the correlation of field-measured $\mathrm{pH}$ and DO. It is therefore reasonable to suggest that respiration/remineralization-derived $\mathrm{CO}_{2}$ had increased the acidity in the bottom oxygen-depleted waters of northwestern-northern near-shore areas in the Bohai Sea. According to the marine environmental bulletin released by the National Marine Environmental Monitoring Center of China, five cases of red tides were recorded in the Bohai Sea in July 2011 alone (http: //www.mem.gov.cn/hyxx/index.htm). The biogenic particles produced by these red tides can undoubtedly support a high respiration/remineralization rate in the bottom waters to consume bottom DO and release acidic $\mathrm{CO}_{2}$.

It is worth noting that the respiration/remineralizationrelated biogenic particles may have multiple sources. Both red tides and self-pollution of marine aquaculture [27] can introduce biogenic particles into the system and lead to near-shore bottom DO depletion and coastal acidification. To better constrain the sources of biogenic particles causing those coastal acidification events in the Bohai Sea in August 2011, further investigations are needed.

To maintain a low-DO/low-pH bottom environment in a shallow-water near-shore area, turbulent mixing and air-sea exchanges have to be blocked by vertical stratification. According to a numerical simulation study, the Bohai Sea is vertically stratified from early April to early September every year [25]. Based on our CTD measurements, vertical stratification was enhanced from June to August in 2011 in the northwestern-northern near-shore areas of the Bohai Sea (Figure 2). This status certainly obstructed the recovery of bottom DO values and the release of free $\mathrm{CO}_{2}$. In the southern part of the Bohai Sea, however, efficient turbulent mixing in water columns (CTD data not reported) fully destroyed the accumulated effects of possible DO depletion and $\mathrm{CO}_{2}$ release. Apparently, both bottom $\mathrm{DO}$ and $\mathrm{pH}$ were at relatively high levels in the southern part of the Bohai Sea (Figure 4).

In summary, we observed summer bottom oxygen depletion and acidification in northwestern-northern near-shore areas in the Bohai Sea from June to August in 2011. Based on field measurements of bottom $\mathrm{DO} / \mathrm{pH}$, combined with a simplified model simulation, we suggest that respiration/ remineralization-derived $\mathrm{CO}_{2}$ increased the acidity of bottom oxygen-depleted waters of northwestern-northern nearshore areas of the Bohai Sea; this was caused by coastal red tides and/or marine aquaculture. Water stratification in summer also contributed to the formation of seasonally oxygendepleted and acidified bottom habitats. The seasonal bottom oxygen-depletion in the Bohai Sea was close to hypoxia, and the associated short-term acidification was comparable to reported coastal acidification in typical coastal hypoxic regions in the northern Gulf of Mexico and in the northwestern East China Sea off the Changjiang Estuary. This supports the idea that the marine ecosystems in the northwestern-northern near-shore areas in the Bohai Sea are on a critical path of environmental degradation. It is not clear how marine organisms (especially calcifying species) and biogeochemical patterns (including geochemistry in sediments) will be affected by the double stresses of coastal acidification and shortages of DO. These problems are worth serious investigation in the future.

We thank Dr. Shaoling Shang's group for chlorophyll a data support, and Drs. Juying Wang and Jun Sun for their constructive discussion. Houjie Wang, Xiao Huang, Kunpeng Zang, Yuewen Jiang, Minghao Li and the crews of $R / V$ Dongfanghong II and $R / V$ Yixing provided much help during the sampling cruises. Dr. Paolo Domenici is sincerely thanked for his comments and assistance with English. We are grateful to Helen McPherson and two anonymous reviewers for their constructive comments and suggestions on the manuscript. This work was supported by the National Basic Research Program of China (2009CB421204) and the National Natural Science Foundation of China (NSFC) (41076044 and 40876040). Sampling cruises were supported by the NSFC (41049901) and the State Oceanic Administration of China (contract DOMEP-MEA-01-10).

1 Díaz R J, Rosenberg R. Spreading dead zones and consequences for marine ecosystems. Science, 2008, 321: 926-929

2 Rabalais N N, Turner R E, Justic D, et al. Characterization of Hypoxia: Topic 1 Report for the Integrated Assessment on Hypoxia in the Gulf of Mexico. NOAA Coastal Ocean Program Decision Analysis Series No.15. Silver Spring (MD): NOAA Coastal Ocean Program, 1999

3 Li D J, Zhang J, Huang D J, et al. Oxygen depletion off the Changjiang (Yangtze River) Estuary. Sci China Ser D-Earth Sci, 2002, 45: 1137-1146

4 Zhang J, Gilbert D, Gooday A J, et al. Natural and human-induced hypoxia and consequences for coastal areas: Synthesis and future development. Biogeosciences, 2010, 7: 1443-1467

5 Wu R S S. Hypoxia: From molecular responses to ecosystem responses. Mar Pollut Bull, 2002, 45: 35-45

6 Vaquer-Sunyer R, Duarte C M. Thresholds of hypoxia for marine biodiversity. Proc Natl Acad Sci USA, 2008, 105: 15452-15457

7 Díaz R J, Breitburg D L. The hypoxic environment. In: Richards J G, Farrell A P, Brauner C J, eds. Hypoxia. Fish Physiology, Vol. 27. Burlington: Academic Press, 2009. 1-23

8 Vaquer-Sunyer R, Duarte C M. Temperature effects on oxygen thresholds for hypoxia in marine benthic organisms. Glob Change Biol, 2011, 17: 1788-1797

9 Zhu B H, Wang G C, Huang B, et al. Effects of temperature, hypoxia, ammonia and nitrate on the bleaching among three coral species. Chin Sci Bull, 2004, 49: 1923-1928

10 Dickson A G, Sabine C L, Christian J R. Guide to best practices for ocean $\mathrm{CO}_{2}$ measurements. PICES Spec Publ 3. 2007

11 Marion G M, Millero F J, Camões M F, et al. pH of seawater. Mar Chem, 2011, 126: 89-96

12 Pelletier G J, Lewis E, Wallace D W R. CO2SYS.XLS: A calculator for the $\mathrm{CO}_{2}$ system in seawater for Microsoft Excel/VBA. Version 14. 
Olympia (Washington): Washington State Department of Ecology. 2007

13 Gao K S, Aruga Y, Asada K, et al. Calcification in the articulated coralline alga Carollina pilulifera, with special reference to the effect of elevated $\mathrm{CO}_{2}$ concentration. Mar Biol, 1993, 117: 129-132

14 Zeebe R E, Zachos J C, Caldeira K, et al. Carbon emissions and acidification. Science, 2008, 321: 51-52

15 Yuan Y X, Chen J F, Chen B J, et al. Study on adaptability of scallop Chlamys farreri to environment: Effects of salinity and $\mathrm{pH}$ on survival, respiration, ingestion and digestion (in Chinese). J Fish Sci Chin, 2000, 7: 73-77

16 Hall-Spencer J M, Rodolfo-Metalpa R, Martin S, et al. Volcanic carbon dioxide vents show ecosystem effects of ocean acidification. Nature, 2008, 454: 96-99

17 Munday P L, Dixson D L, McCormick M I, et al. Replenishment of fish populations is threatened by ocean acidification. Proc Natl Acad Sci USA, 2010, 107: 12930-12934

18 Domenici P, Allan B, McCormick M I, et al. Elevated carbon dioxide affects behavioural lateralization in a coral reef fish. Biol Lett, 2011, doi: 10.1098/rsbl.2011.0591

19 Feely R A, Alin S R, Newton J, et al. The combined effects of ocean acidification, mixing, and respiration on $\mathrm{pH}$ and carbonate saturation in an urbanized estuary. Estuar Coast Shelf Sci, 2010, 88: 442-449
20 Byrne R H, Mecking S, Feely R A, et al. Direct observations of basin-wide acidification of the North Pacific Ocean. Geophys Res Lett, 2010, 37: L02601

21 Cai W J, Hu X P, Huang W J, et al. Acidification of subsurface coastal waters enhanced by eutrophication. Nat Geosci, 2011, 4: 766-770

22 Lin F A, Lu X W, Luo H, et al. History, status and characteristics of red tide in Bohai Sea (in Chinese). Mar Environ Sci, 2008, 27(Suppl 2): $1-5$

$23 \mathrm{Zu} \mathrm{T} \mathrm{T,} \mathrm{Bao} \mathrm{X} \mathrm{W,} \mathrm{Xie} \mathrm{J,} \mathrm{et} \mathrm{al.} \mathrm{Distribution} \mathrm{and} \mathrm{variation} \mathrm{trends} \mathrm{of} \mathrm{the}$ environmental factors in the central section of the Bohai Sea (in Chinese). Period Ocean Univ Chin, 2005, 35: 889-894

24 Ning X R, Lin C L, Su J L, et al. Long-term environmental changes and the responses of the ecosystems in the Bohai Sea during 19601996. Deep-Sea Res II, 2010, 57: 1079-1091

25 Zhou F, Huang D J, Su J L. Numerical simulation of the dual-core structure of the Bohai Sea cold bottom water in summer. Chin Sci Bull, 2009, 54: 4520-4528

26 Chen C C, Chiang K P, Gong G C, et al. Importance of planktonic community respiration on the carbon balance of the East China Sea in summer. Global Biogeochem Cycles, 2006, 20: GB4001

27 Cui Y, Chen B J, Chen J F. Evaluation on self-pollution of marine culture in the Yellow Sea and Bohai Sea (in Chinese). Chin J Appl Ecol, 2005, 16: 180-185

Open Access This article is distributed under the terms of the Creative Commons Attribution License which permits any use, distribution, and reproduction in any medium, provided the original author(s) and source are credited. 